Abstracta Iranica Abstracta Iranica

Revue bibliographique pour le domaine irano-aryen

Volume 28 | 2007

Comptes rendus des publications de 2005

\title{
Canzoniere. A cura di Stefano Pellò e Gianroberto Scarcia, Milano, Ariele, lo scaffale di Mecenate, 2005, xxxii + 732 p. [italien-persan]
}

Justine Landau

\section{(2) OpenEdition Journals}

Édition électronique

URL : http://journals.openedition.org/abstractairanica/20721

DOI : 10.4000/abstractairanica.20721

ISSN : 1961-960X

Éditeur :

CNRS (UMR 7528 Mondes iraniens et indiens), Éditions de l'IFRI

\section{Édition imprimée}

Date de publication : 15 mai 2007

ISSN : 0240-8910

Référence électronique

Justine Landau, « Canzoniere. A cura di Stefano Pellò e Gianroberto Scarcia, Milano, Ariele, lo scaffale di Mecenate, 2005, xxxii + 732 p. [italien-persan] », Abstracta Iranica [En ligne], Volume 28 | 2007, document 334, mis en ligne le 18 septembre 2007, consulté le 25 septembre 2020. URL : http:// journals.openedition.org/abstractairanica/20721; DOI : https://doi.org/10.4000/abstractairanica 20721

Ce document a été généré automatiquement le 25 septembre 2020.

Tous droits réservés 


\section{Canzoniere. A cura di Stefano Pellò e Gianroberto Scarcia, Milano, Ariele, lo scaffale di Mecenate, 2005, xxxii + 732 p. [italien-persan]}

Justine Landau

Deux événements remarquables viennent de bouleverser, à un an d'intervalle, la réception de Ḥāfez en Occident. Deux traductions intégrales du Dìvān paraissent presque simultanément, l'une en italien, l'autre en français. L'une et l'autre sont sans précédent dans leur langue respective, et renouvellent profondément l'approche du poète et de son œuvre. De la superbe traduction commentée de Charles-Henri de Fouchécour (Hâfez de Chiraz, Le Divān. CEuvre lyrique d'un spirituel en Perse au XIVe siècle, Lagrasse, Verdier/poche), parue en 2006, le prochain numéro d'Abs. Ir. fournira un compte-rendu spécifique. Signalons toutefois qu'en dépit d'approches sensiblement différentes, les deux versions, française et italienne, partagent plus d'un point commun. En particulier, toutes deux se fondent sur l'édition du Dìvān par Parvīz Nātel Hูānlarī.

2 La traduction italienne à quatre mains de Stefano Pellò et Gianroberto Scarcia est, pour sa part, tout à fait exemplaire. La lecture du texte de Ḥăfez qu'elle illustre, justifiée dans le paratexte, se fonde sur des prises de position nettes dans les grands débats que suscite son interprétation, tant en Iran que parmi les orientalistes. D'une part, les AA. se refusent à toute interprétation biographique de l'imagerie poétique: amour terrestre ou amour divin, il n'y a pas à choisir. Le texte présente avant tout une fiction littéraire qu'on chercherait en vain à réduire à une figure historique de l'auteur, pas plus libertin qu'il ne fut un «mystique » (les traducteurs, comme d'ailleurs CharlesHenri de Fouchécour, ne recourent à ce terme qu'avec la plus grande prudence, et entre parenthèses). Le trope de prédilection de Ḥăfez est justement l'amphibologie, ambivalence constitutive du texte qui désamorce les velléités de littéralisme. Le choix d'une approche strictement littéraire, qui voit dans les motifs du poème non pas un 
référent, mais un intertexte, permet de conclure sur ce point que « le mysticisme peut être considéré comme une fonction stylistique fondamentale du gazal hafezien ». Grands connaisseurs de la poétique persane, les traducteurs insistent en revanche sur l'inscription de Ḥāfeẓ dans la tradition poétique qui le précède et sur le contexte curial de sa production. D'autre part, la «question hafezienne » de l'unité des gazal soulevée par la réception orientaliste depuis Sir William Jones est clairement tranchée: les traducteurs sont les tenants d'une cohérence interne du texte poétique, qu'ils veulent rendre sensible dans leur traduction. Le texte italien, en vers libres, vise la lisibilité. Les collaborateurs ont opté pour une langue italienne vivante, rétive aux contorsions imposées par tout asservissement littéraliste au texte persan. Ils s'efforcent en outre de préserver le potentiel évocateur du texte, et d'en élucider le "symbolisme chiffré " sans l'alourdir de paraphrase.

3 Un texte aéré, un appareil critique clair et explicatif sans prolixité (préface de G. Scarcia; notes, glossaire des motifs récurrents, et introduction en trois temps portant sur la biographie et la transmission du texte, la tradition du gazal persan, puis le soufisme et le sens du Dìvān par S. Pellò), font de cette édition bilingue un outil de référence tant pour le grand public que pour l'étudiant ou le chercheur, et facilite l'accès du public italien au texte du contemporain persan de Pétrarque. Une parution à saluer pour son audace et sa qualité.

\section{INDEX}

Thèmes : 11.1.1. Littérature persane classique

\section{AUTEURS \\ JUSTINE LANDAU}

Paris 